\title{
MnS Precipitation Behavior of High-Sulfur Microalloyed Steel Under Sub-rapid Solidification Process
}

\author{
WANLIN WANG, CHENYANG ZHU, JIE ZENG, CHENG LU, PEISHENG LYU, \\ HAIRUI QIAN, and HUI XU
}

\begin{abstract}
A typical high-sulfur microalloyed steel was investigated by a sub-rapid solidification process for grain refinement of the as-cast microstructure. The size and distribution characteristics of the $\mathrm{MnS}$ precipitates were analyzed. The variations in the dendrite morphology and secondary dendrite arm spacing (SDAS) under different cooling rates have been studied, which strongly influence the precipitation behavior of $\mathrm{MnS}$. The 3D-morphology of $\mathrm{MnS}$ precipitates was revealed by a novel saturated picric acid deep-etching method. Most MnS precipitates with a length smaller than $5 \mu \mathrm{m}$ were columnar or equiaxed in the corresponding dendrite zones under sub-rapid solidification conditions at cooling rates of 261 to $2484 \mathrm{~K} / \mathrm{s}$. Furthermore, an area scan analysis of the precipitates showed the number of small $\mathrm{MnS}$ per square millimeter with lengths lower than $3 \mu \mathrm{m}$ decrease from 200,537 to 110,067. The percentage of large MnS with a length over $5 \mu \mathrm{m}$ increased from 2.6 to $6.2 \mathrm{pct}$ as the solidification condition changed from sub-rapid to air cooling. In addition, the size of $\mathrm{MnS}$ precipitate was found to depend linearly on the SDAS.
\end{abstract}

https://doi.org/10.1007/s11663-019-01752-4

(c) The Minerals, Metals \& Materials Society and ASM International 2019

\section{INTRODUCTION}

HiGH-STRENGTH medium carbon sulfur-containing microalloyed steels have been widely used in hot forging parts of automobiles, such as crankshafts and connecting rods, due to the advantage of energy-savings with elimination of traditional quenching and tempering processes ${ }^{[1,2]}$ During the continuous casting process of this type of steels, the precipitation behavior of $\mathrm{MnS}$ is crucial, as $\mathrm{MnS}$ precipitates are good lubricants for improving the cutting performance of microalloyed steels. MnS precipitates in as-cast steel slabs can be typically classified according to the morphology: globular MnS (Type I); fine rod-like MnS (Type II); and angular MnS (Type III). ${ }^{[3]}$ It is well known that the mechanical properties of high-sulfur steels are closely related to the MnS precipitates' shape and distribution. ${ }^{[4]}$ In traditional continuous casting of sulfurized steels, the size of $\mathrm{MnS}$ precipitates is generally larger

WANLIN WANG, CHENYANG ZHU, JIE ZENG, CHENG LU, PEISHENG LYU, HAIRUI QIAN, and HUI XU are with the School of Metallurgy and Environment, Central South University, Changsha 410083, P.R. China and also with the National Center for International Research of Clean Metallurgy, Central South University, Changsha 410083, P.R. China. Contact e-mail: zengjie2014@126.com Manuscript submitted August 8, 2019.

Article published online December 12, 2019. than $10 \mu \mathrm{m} \cdot{ }^{[5]}$ In order to obtain better cutting performance, the blooms require prolonged heat treatments to decompose the $\mathrm{MnS}$ precipitates into finer rod-like shapes (Type II) having a mean length lower than 5 $\mu \mathrm{m} .{ }^{[6]}$ This extended heat treating processes would consume significant amounts of additional energy. Therefore, less energy-intensive new production methods to ensure finely dispersed $\mathrm{MnS}$ inclusions in high sulfur-containing microalloyed steels are necessary. Lower sulfur segregation and finer as-cast microstructure with increasing of solidification cooling rates could reduce the precipitation and growth of sulfide. ${ }^{[7,8]}$

As the only industrialized sub-rapid solidification process, strip casting is an important technological revolution for the steel industry, which can produce thin strips directly from the liquid metal. Strip casting has the potential to greatly reduce operating and investment costs through the elimination of multiple rolling steps. ${ }^{[9,10]}$ Strip casting has been known to provide solutions for steels with difficult casting issues including macro-segregation, precipitation of large inclusions, larger structures. Due to the rapid cooling experienced during strip casting, the morphology of as-cast microstructure could be significantly refined ${ }^{[11,12]}$ Electrical steels, ${ }^{[13]}$ TRIP steels, ${ }^{[14]}$ dual phase (DP) steels, ${ }^{[15]}$ and other special steels with complex and non-uniform morphologies have been identified as potential products applicable for strip casting. Some past publications have 
reported the formation of fine manganese sulfides during rapid solidification of low-sulfur steels, such as stainless steels and high-strength low-alloy steels. ${ }^{[8,16]}$

However, there has been limited research related to strip casting of high-sulfur microalloyed steels. In particular, studies on the relationship between the secondary arm dendrite spacing (SADS), cooling rate, and mean length of $\mathrm{MnS}$ precipitates have yet to be studied to the knowledge of the present authors. The aim of this work is to present a novel method for controlling $\mathrm{MnS}$ precipitation via sub-rapid solidification process and reveal the relationship between the distribution characteristics and size of $\mathrm{MnS}$ precipitates, cooling rate, and SDAS of the as-cast structure.

\section{EXPERIMENTAL ARRANGEMENT}

\section{A. Sample Preparation}

The steel sample was in an as-cast condition produced from bloom continuous casting. The typical high-sulfur microalloyed steel samples were cut into cylinders of diameter $7 \mathrm{~mm}$ and height $1.6 \mathrm{~mm}$ weighing about $5.0 \mathrm{~g}$ $( \pm 0.05 \mathrm{~g})$. The chemical compositions are shown in Table I. The samples were polished with an abrasive paper of grit number 400 to remove the oxidized surface and then cleaned in ethanol with ultrasonic agitation prior to the droplet solidification test.

\section{B. Experimental Apparatus and Procedure}

The experimental apparatus for the in-situ observation of the solidification phenomena of the molten metal droplets impinging onto a water-cooled copper substrate was modified from past publications. ${ }^{[10,17-21]}$ A schematic illustration of the system is shown in Figure 1.
The droplet solidification testing system consists of two parts: droplet ejection and data acquisition. The liquid droplet is obtained by heating the metal specimen using induction coils. The ejection of molten droplets to the copper mold is conducted through a pulse of high-purity Ar (99.999 vol pct). The atmosphere control system allows the control of the oxygen partial pressure. This system allows the metal melting and dropping on the substrate surface under controlled temperature and atmosphere.

Prior to the experiment, the copper mold substrate is cleaned and polished with an abrasive paper of grit number 3500 to ensure comparable surface roughness for each experiment. The oxygen partial pressure is lower than $10^{-5}$ atm through a stream of high-purity Ar (99.999 vol pct). The metal specimen is placed within a quartz tube that has a small hole on the bottom. The specimen lies in the middle of the induction coil installed inside the bell jar, where a controlled atmosphere can be ensured. The sample is heated and melted using the induction furnace, and the temperature was measured with a pyrometer placed above the tube. A PID controller receives the temperature signals from the pyrometer and controls the target temperature by adjusting the power of the induction furnace. When the desired temperature is reached, the liquid droplet is ejected through the small hole at the bottom of the tube with the help of a pulse of high-purity Ar (99.999 pct). The droplet subsequently impinges onto the water-cooled copper substrate and solidifies. A charge coupled device (CCD) camera is placed adjacent to the bell jar to record the entire melting and solidification process of the sample.

The target temperature of the liquid metal before ejection is $1550{ }^{\circ} \mathrm{C}$. In order to obtain samples with different cooling rates, one melt sample was retained in the quartz tube and subject to air cooling, and the other melt sample was ejected onto the surface of the water-cooled copper substrate for sub-rapid cooling.

Table I. The Main Chemical Composition of the High-Sulfur Microalloyed Steel (in Mass Percent)

\begin{tabular}{lcccccccccc}
\hline Element & $\mathrm{C}$ & $\mathrm{Si}$ & $\mathrm{Mn}$ & $\mathrm{P}$ & $\mathrm{S}$ & $\mathrm{Nb}$ & $\mathrm{V}$ & $\mathrm{Ti}$ & $\mathrm{Fe}$ \\
\hline Content & 0.46 & 0.35 & 0.71 & 0.0075 & 0.055 & 0.022 & 0.094 & 0.034 & bal \\
\hline
\end{tabular}

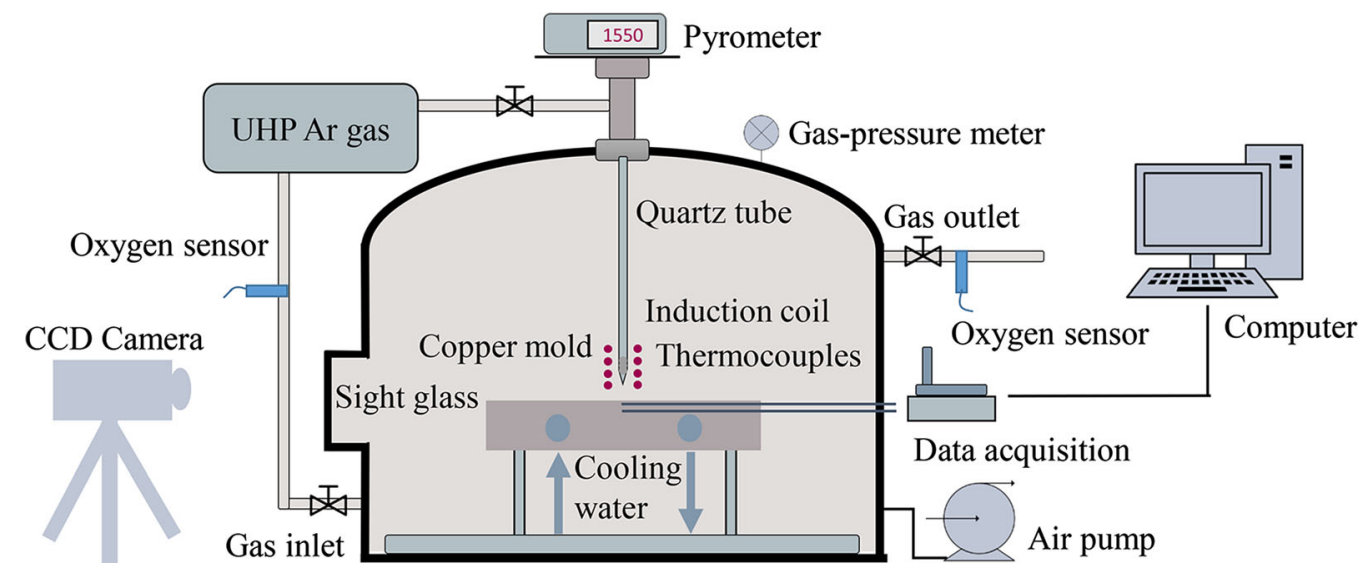

Fig. 1-Schematic illustration of the droplet solidification test. 


\section{Analysis Method}

The solidified samples were cut into halves along the longitudinal direction and prepared through standard metallographic procedures for cross-sectional analysis. In addition, a novel saturated picric acid deep-etching method was developed to reveal the 3D-morphology of $\mathrm{MnS}$ precipitates. The samples were subject to morphological examinations using optical microscopy (OM, Jiangnan MR5000, China), scanning electron microscopy (SEM, TESCAN MIRA 3 LMU, Czech) equipped with X-ray energy-dispersive spectrometer (EDS, Oxford X-Max20, England), and electron probe micro-analysis (EPMA, JEOL JXA-8530F, City, Japan) equipped with wavelength dispersive X-ray spectrum system (WDS, XM-86030). The hardness of the samples was identified using a microhardness tester (HMV-2T, Japan). The number and size of $\mathrm{MnS}$ precipitates were analyzed by an inclusion automatic detection scanning electron microscopy (ASPEX). The secondary dendrite arm spacing and mean size of $\mathrm{MnS}$ precipitates in the as-cast microstructures were analyzed by GetData software from the OM and SEM images.

\section{RESULTS AND DISCUSSION}

\section{A. Droplet Process}

A typical experiment conducted for the high-sulfur microalloyed steel droplet from ejection to solidification is provided in Figure 2. The sample is initially heated in the quartz and the initiation of ejection occurs after about 25.9 seconds (Figures 2(a) and (b)). The molten droplet then forms a hemispherical shape on the substrate after ejection and rapidly solidified (Figures 2(b) through (c)). Finally, the temperature of the sample cools down rapidly in less than 10 seconds (Figures 2(b) through (d)).

\section{B. Microstructure}

The microstructure of the solidified droplet is dependent on the heat transfer conditions, and the corresponding dendritic morphology has a significant impact on the internal quality including segregation and porosities of the as-cast ingot. ${ }^{[22]}$ The microalloyed steel droplet solidifies at the bottom in the upward direction away from the copper substrate towards the top (Figure 3(a)). The as-cast microstructure can be divided into three sections of fine, columnar, and equiaxed grain zones due to the different heat transfer conditions. The heat transfer direction is perpendicular to the surface of the mold and a small amount of convective heat transfer is also occurring with the atmosphere along the perpendicular direction of the droplet/gas interface. The morphological characteristics identified in the sub-rapid solidification droplet were consistent with industrial strip cast samples that also show three solidification zones similar to the present work. ${ }^{[1]}$ The other aircooled sample was solidified from the periphery to the core of the body within the quartz tube (Figure 3(b)). Contrary to the sub-rapid solidified sample, it showed two sections of columnar and equiaxed grain zones due to the much lower cooling rate. It is obvious that the dendrites and grains in the water cooling sample are much finer than the air-cooled sample.

\section{Identification of the $S D A S$}

To quantify the dendrite size, the secondary dendrite arm spacing (SDAS) is closely related to the cooling process and utilized to characterize the solidification behavior. In particular, it can be used to evaluate the grain refinement and segregation degree. ${ }^{[23]}$ The SDAS of as-solidified droplets measured in multiple dendritic regions is provided in Figure 3. An average of the multiple measurements was taken and the standard

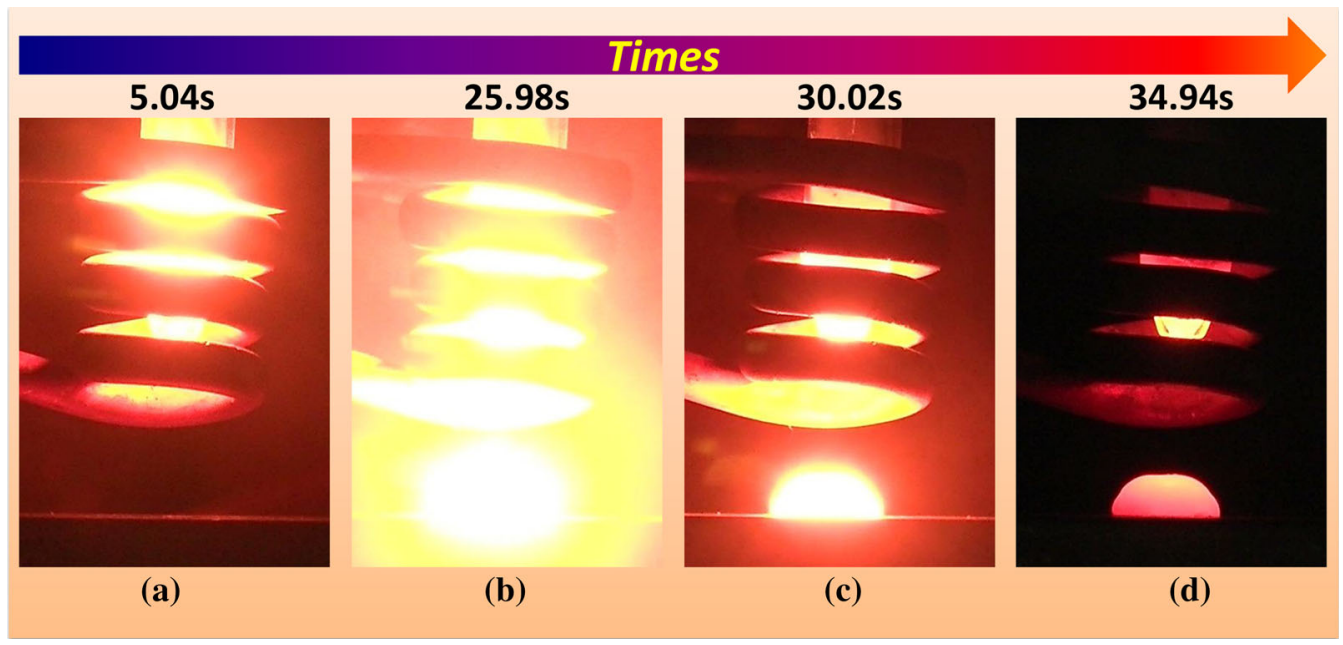

Fig. 2-The droplet solidification process: $(a)$ the heating before ejection, $(b)$ the start of ejection, $(c)$ and $(d)$ the cooling on the water-chilled copper. 


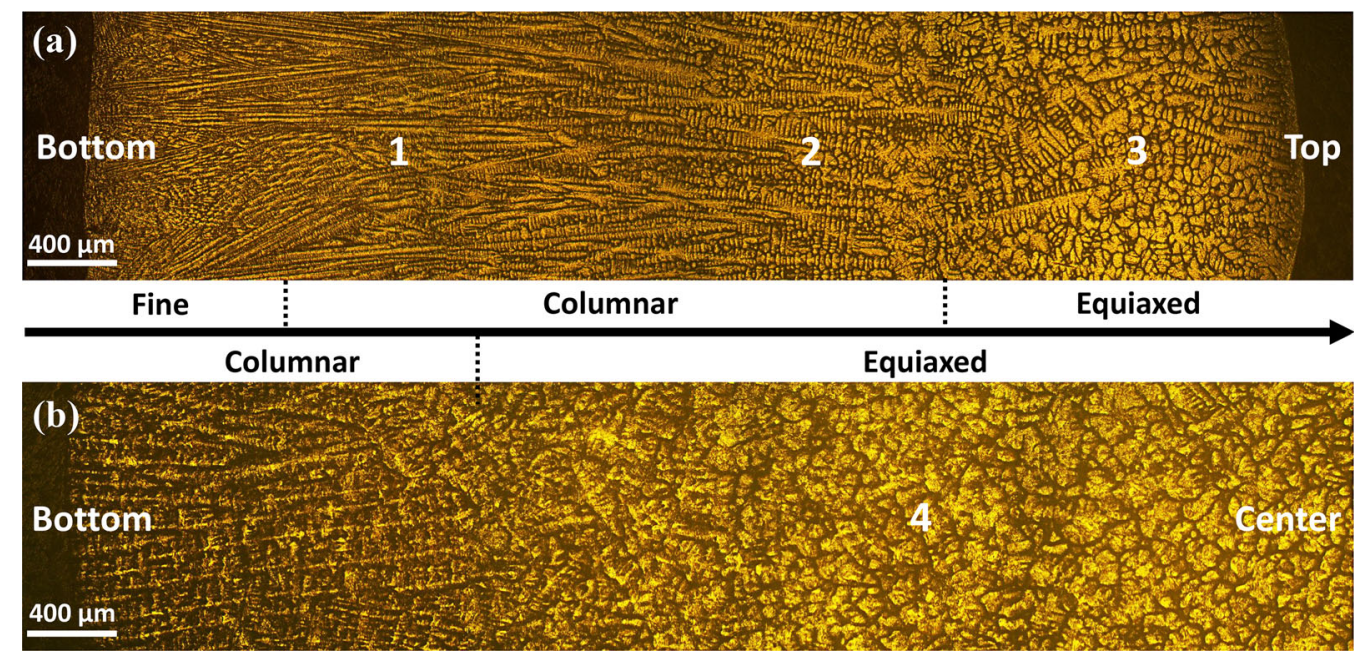

Fig. 3-Typical dendritic structures of the solidified samples: (a) sub-rapid solidified droplet, $(b)$ quartz tube solidified sample.

Table II. The SDAS and Corresponding Calculated Cooling Rates

\begin{tabular}{lcccc}
\hline Positions & 1 & 2 & 3 & \multicolumn{1}{c}{} \\
\hline SDAS $(\mu \mathrm{m})$ & 11.56 & 17.92 & 26.11 & 42.96 \\
Cooling Rates $(\mathrm{K} / \mathrm{s})$ & 2484 & 739 & 261 & 66 \\
\hline
\end{tabular}

(a)

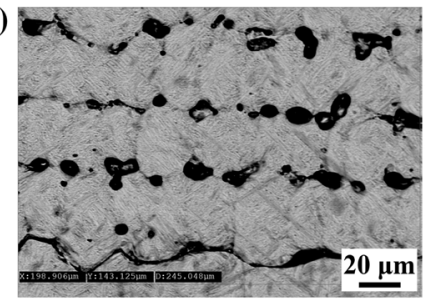

(b)
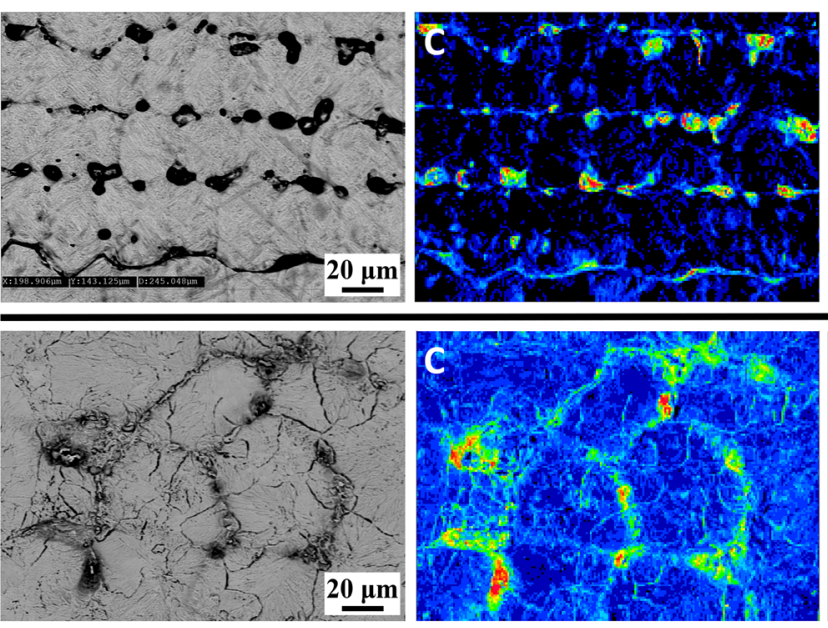
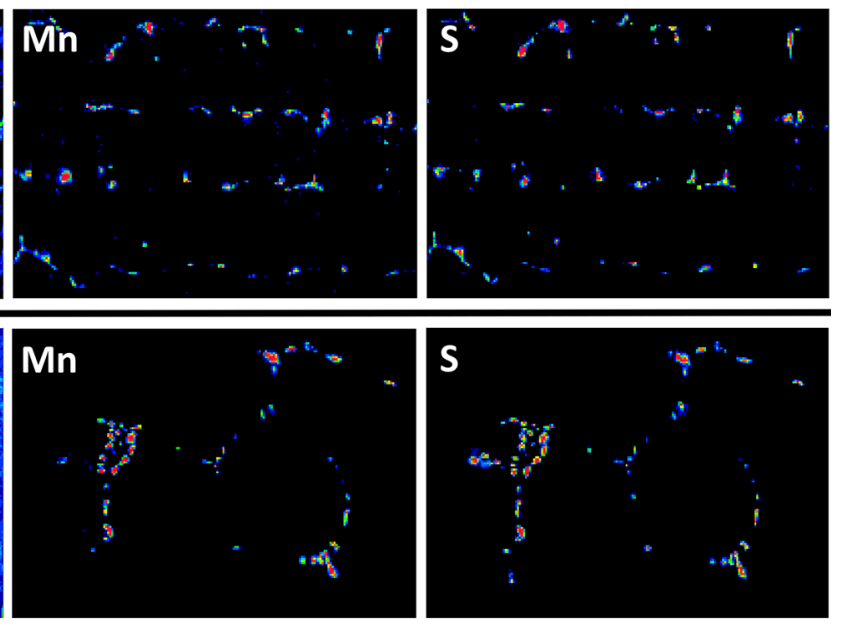

Fig. 4-EPMA analysis of MnS precipitates in (a) positions 2 and (b) position 4 of Fig. 3.

deviations calculated. Position 1 is the bottom of the columnar grain zone, position 2 is the top of the columnar grain zone for the sub-rapid solidified sample. Position 3 is the center of the equiaxed grain zone in the sub-rapid solidified sample. Position 4 is the equiaxed grain zone in the air-cooled sample. The cooling rates were estimated from the secondary dendrite arm spacing in the as-cast structure according to the following equation ${ }^{[24]}$.

$$
\lambda=\left\{\begin{array}{c}
\left(169.1-720.9 w_{[C]}\right) \cdot C_{R}^{-0.4935}, 0<w_{[C]} \leq 0.15 \\
143.9 \cdot C_{R}^{-0.3616} \cdot w_{[C]}^{\left(0.5501-1.996 w_{[C]}\right)}, w_{[C]} \geq 0.15
\end{array}\right.
$$

where the symbol $\lambda$ represents the measured data of secondary dendrite arm spacing, $C_{R}$ is the cooling rate $(\mathrm{K} / \mathrm{s})$, and $w_{[\mathrm{C}]}$ is the carbon content (mass pct). 
The measured SDAS and corresponding calculated cooling rates are shown in Table II. The results indicate that the SDAS of the droplet increases from the bottom $(11.56 \mu \mathrm{m})$ to the top $(26.11 \mu \mathrm{m})$ as the heat transfer varies in the dendrite zone. For comparison, the SDAS of the quartz tube solidified sample increases significantly, with a value of $42.96 \mu \mathrm{m}$ due to a slow cooling rate of $66 \mathrm{~K} / \mathrm{s}$. In the sub-rapid cooled droplet, the corresponding cooling rate of Position 1 near the bottom of the droplet is close to $2500 \mathrm{~K} / \mathrm{s}$ and Position 3 at the top is decreased to $261 \mathrm{~K} / \mathrm{s}$. The cooling rates in these positions correlate to the sub-rapid solidification range. ${ }^{25]}$

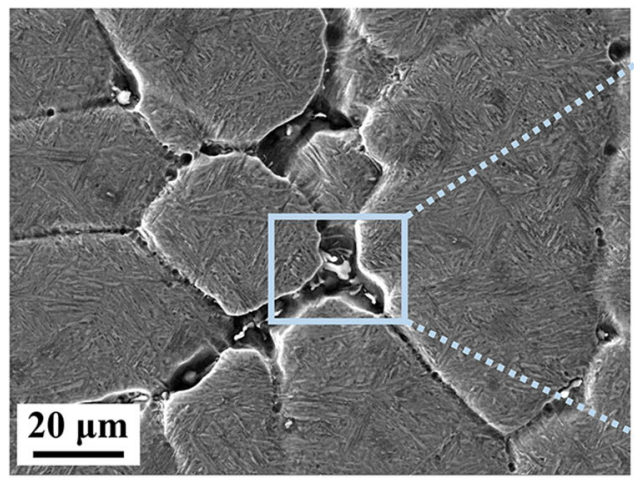

(a)

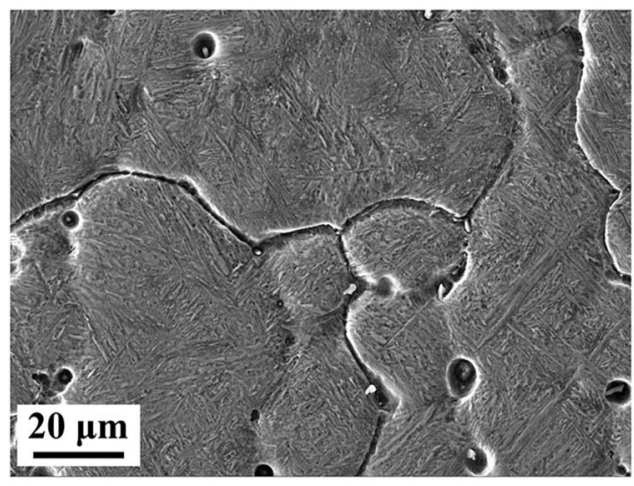

(b)

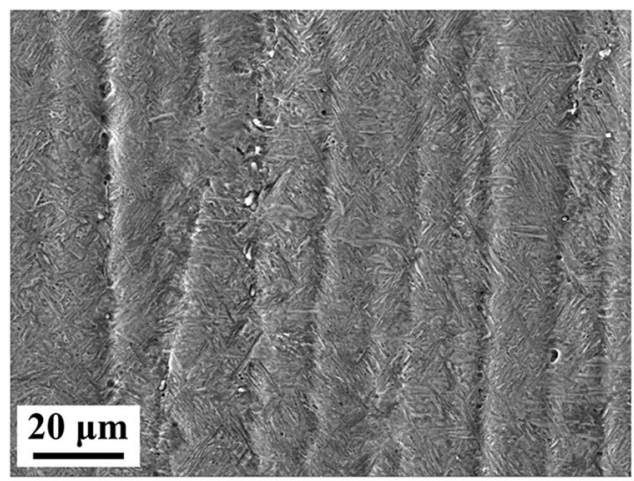

(c)

\section{Distribution of $M n S$}

The distribution characteristics of the $\mathrm{MnS}$ precipitates are investigated by EPMA analysis, as shown in Figure 4. Owing to the serious microsegregation of $\mathrm{S}$ and $\mathrm{Mn}$ elements in the interdendritic regions, the substantial precipitation of $\mathrm{MnS}$ begins at $1410{ }^{\circ} \mathrm{C}$ in the later stages of solidification. ${ }^{[26]}$ It can be found from Figure 4(a) that the distribution of $\mathrm{MnS}$ is distributed along the columnar direction adjacent to the dendrites in the interdentritic region with fast directional cooling conditions. The distribution of $\mathrm{MnS}$ shows a dramatic change with the appearance of a columnar-to-equiaxed transition (CET) at lower cooling rates. For the center equiaxed grain zones, the $\mathrm{MnS}$ is also equiaxed

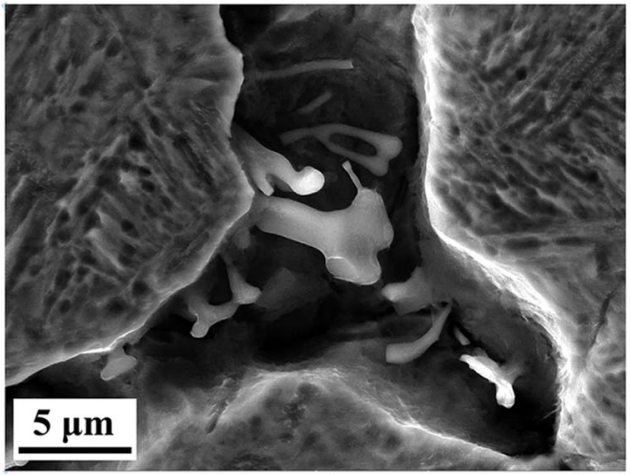

(d)

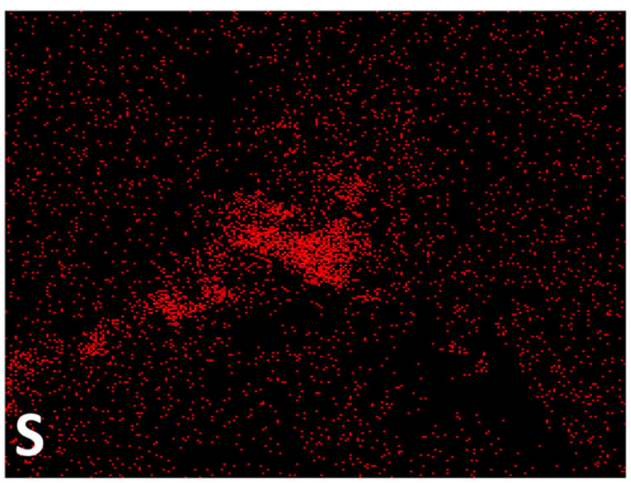

(e)

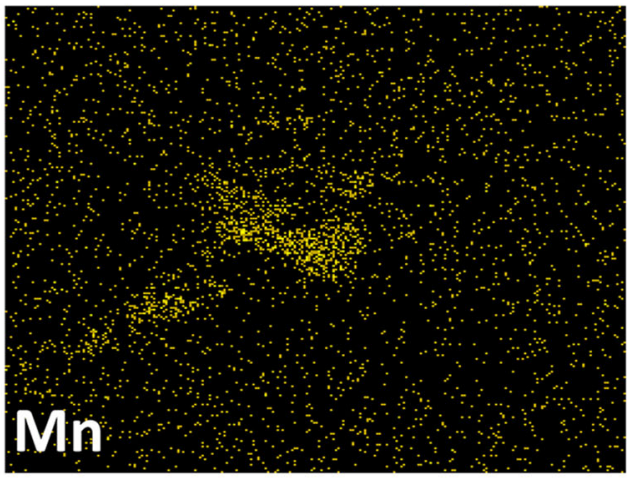

(f)

Fig. 5-Typical SEM and EDS mapping analysis of MnS precipitates in sub-rapid solidified droplet: (a) SEM of position 3 in Fig. 3, (b) SEM of position 2 in Fig. 3, (c) SEM of position 1 in Fig. 3, (d) 3D-Morphological of MnS in position 3, (e) Element S distribution in (d), $(f)$ Element Mn distribution in (d). 
distributed and concentrated along the dendrite boundaries (Figure 4(b)). In the sub-rapid solidification process, elemental segregation could be minimized by higher cooling rates, which can also influence the distribution behavior of precipitants. ${ }^{[27]}$

\section{E. Size of $M n S$}

To reveal the 3D-morphology of $\mathrm{MnS}$ precipitates, the specimens were etched using a saturated picric acid deep-etching method (with a temperature of $70{ }^{\circ} \mathrm{C}$, duration of 20 minutes). The deep-etched surface was cleaned using a polishing cloth with water. The 3D-morphology of MnS can be observed by SEM under secondary electron mode at four typical positions of Figure 3, as shown in Figures 5(d), 6(c) and (d). The EDS mapping of the elements $\mathrm{S}$ and $\mathrm{Mn}$ confirms the precipitation of $\mathrm{MnS}$ in the as-cast structure (Figures 5(e), (f) and 6(e), (f)). It can be observed that the morphology of $\mathrm{MnS}$ has different shapes/types at different positions. As shown in Figure 5(a) through (c), the size of $\mathrm{MnS}$ decreases significantly along the final to the initial solidification position. The $\mathrm{MnS}$ is a large globular-form (Type I) in position 4 (Figures 6(c) and (d)) and becomes a fine rod-like form (Type II) in position 3 (Figure $5(\mathrm{~d})$ ). The variation of $\mathrm{MnS}$ size is closely related to the cooling rate and SDAS, which will be discussed in Section III-F.

The mean length of $\mathrm{MnS}$ precipitates is analyzed through the GetData software after measuring at least thirty different precipitates along one position of the SEM image and the results are shown in Table III. It can be found that the mean length of $\mathrm{MnS}$ precipitates in position 4 of air-cooled droplets $(5.32 \mu \mathrm{m})$ is larger than the sub-rapid solidified droplets (1.98-4.51 $\mu \mathrm{m})$. The mean length of $\mathrm{MnS}$ precipitates in the sub-rapid solidified sample also show variations with each other from 1.98 to $4.51 \mu \mathrm{m}$ due to the different cooling rates from the bottom to the top of the molten droplet.

In order to further compare the length of $\mathrm{MnS}$ precipitates in the sub-rapid and air-cooled samples, a statistical analysis of the size and number of $\mathrm{MnS}$ inclusions is shown in Figure 7. The area scanning (1.49 $\times 10^{4} \mu \mathrm{m}^{2}$ ) of $\mathrm{MnS}$ in positions 2 and 4 represents the sub-rapid and air cooling, respectively. The size distribution of $\mathrm{MnS}$ is mainly focused within the length range of below $3 \mu \mathrm{m}$, which accounts for more than 75 pct of the observed inclusions. In this size range, the number of $\mathrm{MnS}$ inclusions per square millimeter (number density) is 200,537 and 110,067 under the condition of sub-rapid and air-cooled samples, respectively. The number of small MnS inclusions increase with sub-rapid solidification, which suggests higher cooling rates could generate smaller sized $\mathrm{MnS}$ inclusions. In addition, the number density of MnS larger than $5 \mu \mathrm{m}$ is 6376 and 9128 , which accounts for 2.6 and 6.2 pet of the total number of inclusions under sub-rapid and air cooling conditions. The decrease in the large sized $\mathrm{MnS}$ further confirms that the sub-rapid solidification process could reduce the size and thus refine the MnS precipitates.

Moreover, in order to confirm the mechanical properties of $\mathrm{MnS}$, microhardness tests have also been conducted. The results indicate that the average Vickers microhardness value of $\mathrm{MnS}(\sim 167 \mathrm{HV})$ is much smaller

Table III. The Mean Length of MnS Precipitates

\begin{tabular}{lcccc}
\hline Positions & 1 & 2 & 3 & 4 \\
\hline Mean Length of MnS $(\mu \mathrm{m})$ & 1.98 & 3.23 & 4.51 & 5.32 \\
\hline
\end{tabular}

(a)

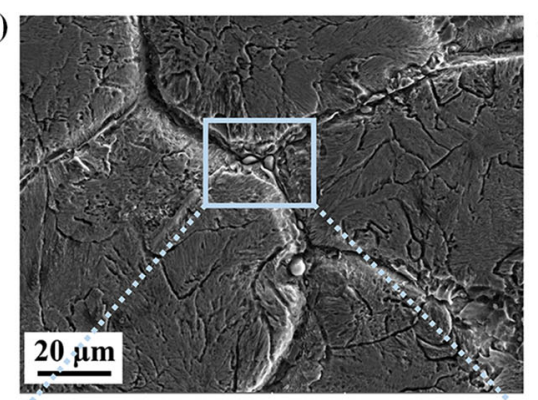

(d)

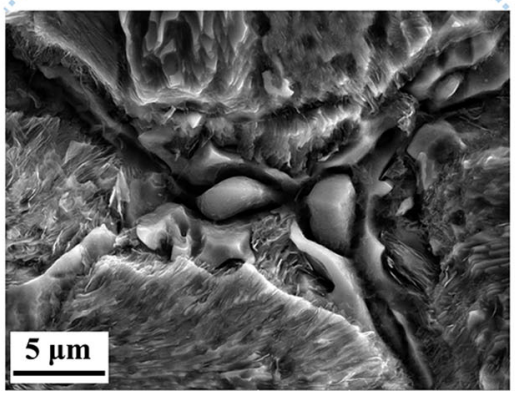

(b)

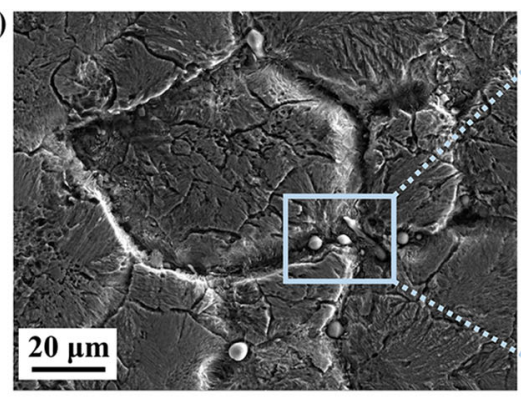

(e)

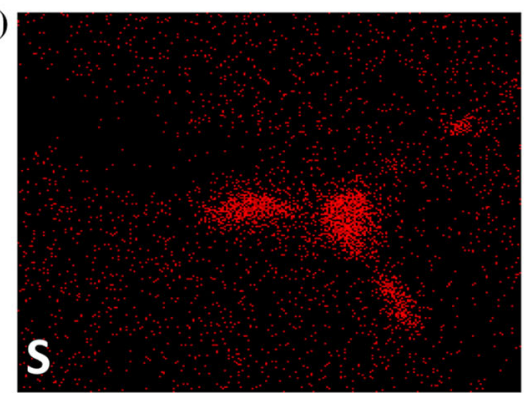

(c)

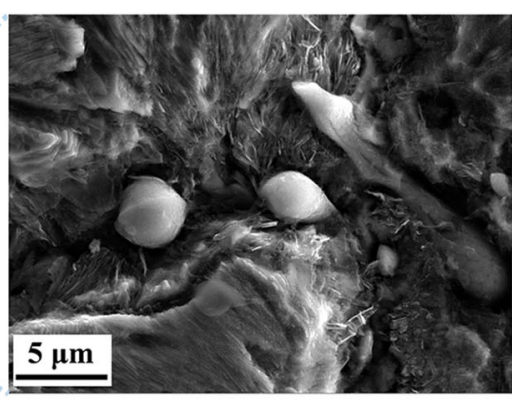

(f)

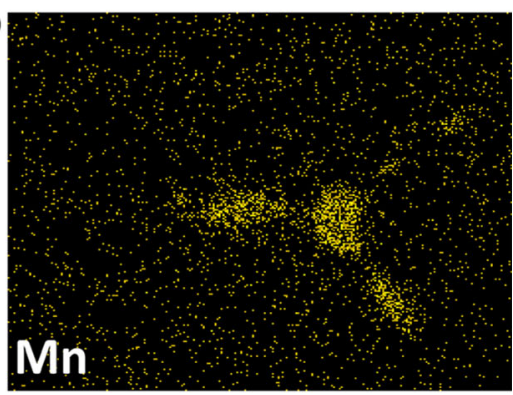

Fig. 6-Typical SEM and EDS mapping analysis of MnS precipitates in air-cooled sample: $(a)$ and $(b)$ SEM of position 4 in Fig. 3, $(c)$ and $(d)$ 3D-Morphological of MnS in position 4 of Fig. 3, (e) Element S distribution in (d), (f) Elements Mn distribution in (d). 


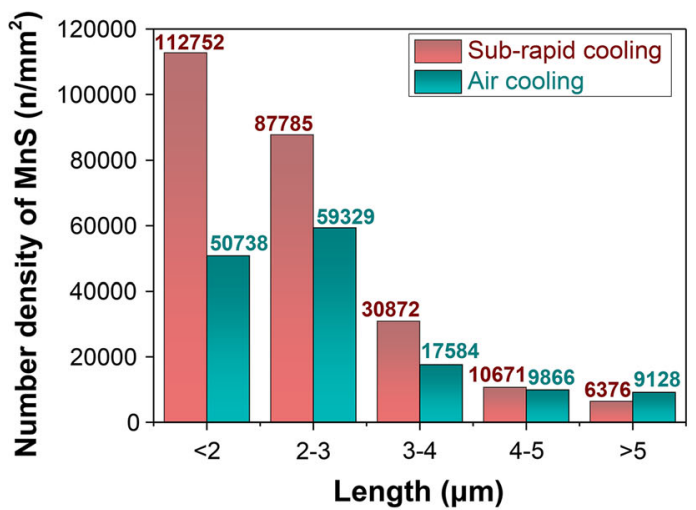

(a)

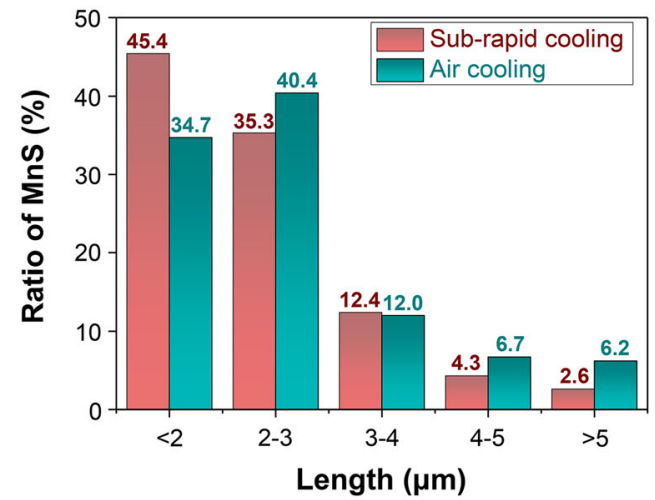

(b)

Fig. 7- Size and number distribution of MnS inclusions for sub-rapid cooling and air cooling conditions: $(a)$ Number density of MnS, (b) Ratio of $\mathrm{MnS}$.

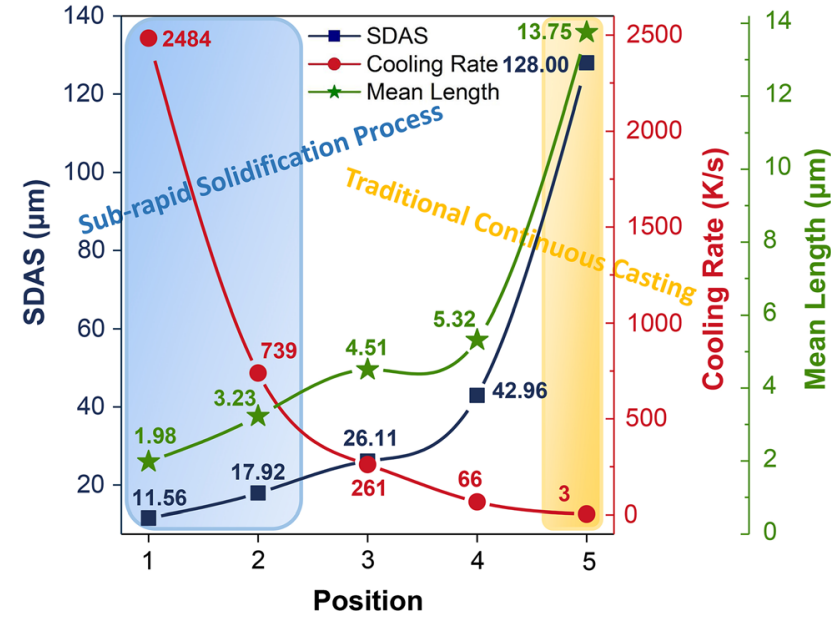

Fig. 8-Interactive relationship between the secondary dendrite arm spacing, cooling rate, and mean length of the precipitated $\mathrm{MnS}$.

than the metal matrix $(\sim 712 \mathrm{HV})$, which further shows the reason behind the good lubrication ability of $\mathrm{MnS}$ to improve the cutting performance of microalloyed steels.

\section{F. Control Mechanism of MnS Precipitates}

In order to better indicate the effect of cooling rate on $\mathrm{MnS}$ precipitation, a comparison between past results from a traditional continuous casting process was compared to the present work. ${ }^{[2]}$ The interactive relationship between the secondary dendrite arm spacing (SDAS), cooling rate, and mean length of the precipitated $\mathrm{MnS}$ is shown in Figure 8. The cooling rate during traditional continuous casting is only $3 \mathrm{~K} / \mathrm{s}$, which is almost $1 / 1000$ of the cooling rate of the sub-rapid solidification process of the present work. Obviously, the size of precipitated $\mathrm{MnS}$ with mean length of $13.75 \mu \mathrm{m}$ in traditional continuous casting is much bigger than in the sub-rapid solidification process $(1.98-4.51 \mu \mathrm{m})$. A distinct reduction of the size of $\mathrm{MnS}$ with decreasing SDAS or increasing cooling rate becomes completely feasible, indicating a shorter growth time of $\mathrm{MnS}$ precipitates.
The quantitative relations between the mean length of $\mathrm{MnS}$ and the SDAS are further analyzed according to the obtained data of Figure 8. The results suggest that the relationship between the measured mean length of $\mathrm{MnS}$ precipitates and the measured SDAS conforms to the following formula:

$$
L=0.098 \lambda+1.455,
$$

where the symbol $\lambda$ represents the secondary dendrite arm spacing $(\mu \mathrm{m})$, and $L$ stands for the mean length $(\mu \mathrm{m})$ of $\mathrm{MnS}$ precipitates. The trend of $\mathrm{MnS}$ is almost in line with the trend of SDAS in the as-cast structure.

As illustrated in Figure 9, the MnS precipitates with smaller sizes are columnar and/or equiaxed distributed in the corresponding dendrite zones with shorter SDAS due to higher cooling rates during sub-rapid solidification. The reduction of the SDAS limits the time and space for further growth of MnS precipitates and further causes a transition of the $\mathrm{MnS}$ morphology from a large globular-form (Type I) to a fine rod-like form (Type II).

It should be noted that the control of MnS precipitation in high-sulfur microalloyed steels using a sub-rapid solidification method was not noticed before because the existing works usually focused on optimizing the traditional continuous casting process and its subsequent heat treating process. The size of $\mathrm{MnS}$ precipitates in the present work is significantly decreased compared to the typical industrial process. The control of $\mathrm{MnS}$ precipitates with a length smaller than $5 \mu \mathrm{m}$ is difficult through the conventional continuous casting process.

\section{CONCLUSIONS}

A typical high-sulfur microalloyed steel has been experimentally investigated by a novel sub-rapid solidification method by analyzing the droplet process, microstructure, cooling rate, distribution, and size of $\mathrm{MnS}$ precipitates. The following are the main conclusions: 


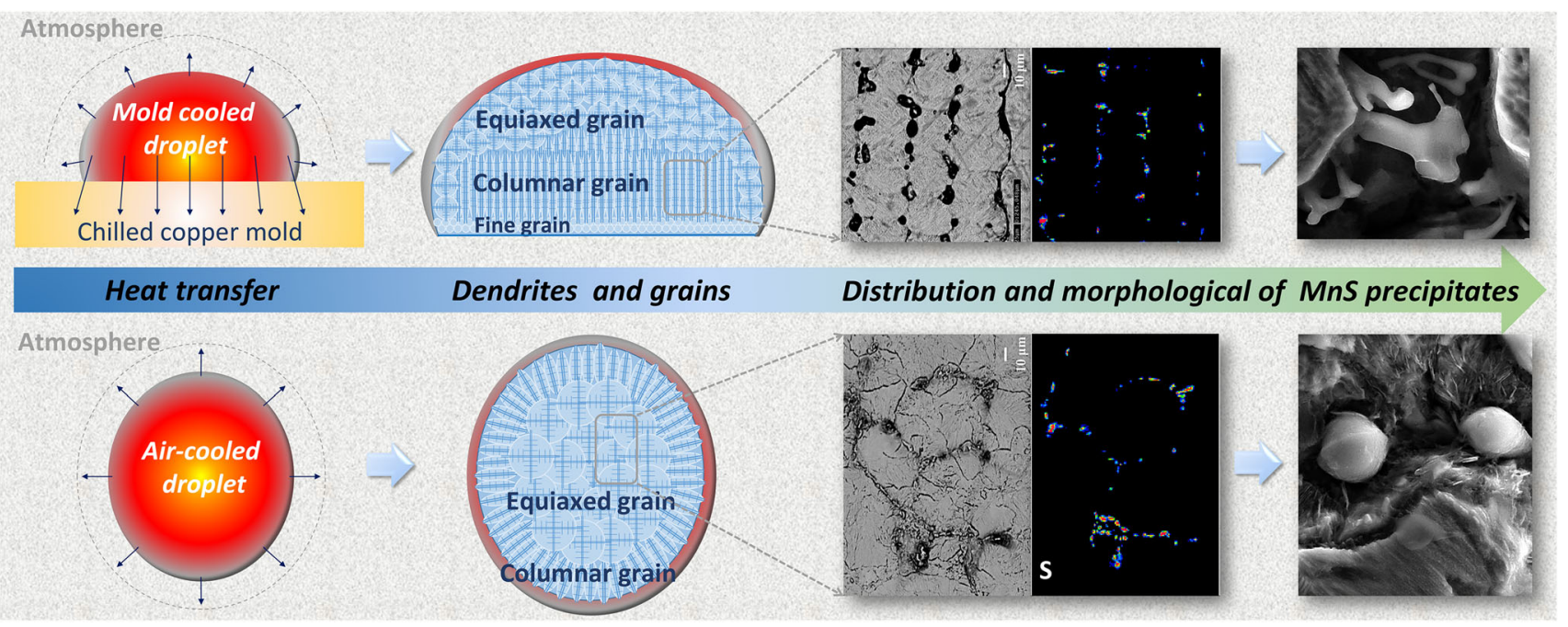

Fig. 9-Schematic illustration of MnS precipitates control mechanism with droplet solidification process.

(1) The 3D-morphology of $\mathrm{MnS}$ precipitate was revealed by a simple saturated picric acid deep-etching method. Most MnS precipitates with a length smaller than $5 \mu \mathrm{m}$ were columnar or equiaxed in the corresponding dendrite zones under sub-rapid solidification conditions at cooling rates of 261-2484 $\mathrm{K} / \mathrm{s}$

(2) As the solidification condition changed from subrapid to air cooling, the number of small $\mathrm{MnS}$ per square millimeter with a length lower than $3 \mu \mathrm{m}$ decreased from 200,537 to 110,067 , and the percentage of the large $\mathrm{MnS}$ with a length over than 5 $\mu \mathrm{m}$ increased from 2.6 to $6.2 \mathrm{pct}$.

(3) The length of $\mathrm{MnS}$ reduced from 4.51 to $1.98 \mu \mathrm{m}$ as the SDAS decreased from 26.11 to $11.56 \mu \mathrm{m}$ due to the different cooling rates from the top to the bottom of the molten droplet. A formula which can be used to predict the size of $\mathrm{MnS}$ precipitates was established.

(4) A novel experimental droplet solidification apparatus was developed to simulate the process of strip casting. The sub-rapid solidification process is probably a viable method for obtaining small rodlike form MnS precipitates and thus may has good prospects for industrial application.

\section{ACKNOWLEDGMENTS}

This work is supported by the National Natural Science Foundation of China (U1760202), Hunan Provincial Key Research and Development Program (2018WK2051), Opening Foundation of the State Key Laboratory of Advanced Metallurgy (KF19-04), Hunan Provincial Innovation Foundation for Postgraduate (CX2018B089), and Fundamental Research Funds for the Central Universities of Central South University (2018zzts018).

\section{REFERENCES}

1. M.J. Balart, C.L. Davis, and M. Strangwood: Mater. Sci. Eng. A, 2000, vol. 284, pp. 1-13.

2. N. Tsunekage and H. Tsubakino: ISIJ Int., 2001, vol. 41, pp. 498505 .

3. C.E. Sims: Trans. Am. Inst. Min. Metall. Eng., 1959, vol. 215, pp. 367-93.

4. M. Wu, W. Fang, R.M. Chen, B. Jiang, H.B. Wang, Y.Z. Liu, and H.L. Liang: Mater. Sci. Eng. A, 2019, vol. 744, pp. 324-34.

5. X.F. Zhang, W.J. Lu, and R.S. Qin: Scr. Mater., 2013, vol. 69, pp. $453-56$.

6. X.J. Shao, X.H. Wang, M. Jiang, W.J. Wang, and F.X. Huang: ISIJ Int., 2011, vol. 51, pp. 1995-2001.

7. Y. Wang, L. Zhang, H. Zhang, X. Zhao, S. Wang, and W. Yang: Metall. Mater. Trans. B, 2017, vol. 48B, pp. 1004-13.

8. S. Malekjani, I.B. Timokhina, J. Wang, P.D. Hodgson, and N.E. Stanford: Mater. Sci. Eng. A, 2013, vol. 581, pp. 39-47.

9. H. Jiao, Y. Xu, W. Xiong, Y. Zhang, G. Cao, C. Li, J. Niu, and R.D.K. Misra: Mater. Design, 2017, vol. 136, pp. 23-33.

10. P. Nolli: PhD Thesis, Carnegie Mellon University, 2007.

11. Z.J. Wang, X.M. Huang, Y.W. Li, G.D. Wang, and H.T. Liu: Mater. Sci. Eng. A, 2019, vol. 747, pp. 185-96.

12. C.Y. Zhu, W.L. Wang, J. Zeng, C. Lu, L.J. Zhou, and J. Chang: ISIJ Int., 2019, vol. 59, pp. 880-88.

13. F. Fang, Y.X. Zhang, X. Lu, Y. Wang, M.F. Lan, G. Yuan, R.D.K. Misra, and G.D. Wang: Scripta Mater., 2018, vol. 147, pp. 33-36.

14. Z.P. Xiong, A.A. Saleh, R.K.W. Marceau, A.S. Taylor, N.E. Stanford, A.G. Kostryzhev, and E.V. Pereloma: Acta Mater., 2017, vol. 134, pp. 1-15.

15. H.S. Wang, G. Yuan, J. Kang, G.M. Cao, C.G. Li, R.D.K. Misra, and G.D. Wang: Mater. Sci. Eng. A, 2017, vol. 703, pp. 486-95.

16. T. Dorin, K. Wood, A. Taylor, P. Hodgson, and N. Stanford: Mater. Charact., 2016, vol. 112, pp. 259-68.

17. P. Nolli and A.W. Cramb: Metall. Mater. Trans. B, 2008, vol. 39B, pp. 56-65.

18. P. Nolli and A.W. Cramb: ISIJ Int., 2007, vol. 47, pp. 1284-93.

19. W.L. Wang, C.Y. Zhu, C. Lu, J. Yu, and L.J. Zhou: Metall. Mater. Trans. A, 2018, vol. 49A, pp. 5524-34.

20. C.Y. Zhu, W.L. Wang, and C. Lu: J Alloys Compd., 2019, vol. 770, pp. 631-39.

21. C. Lu, W.L. Wang, J. Zeng, C.Y. Zhu, and J. Chang: Metall. Mater. Trans. B, 2019, vol. 50B, pp. 77-85.

22. J. Zeng, W. Chen, W. Yan, Y. Yang, and A. McLean: Mater. Des., 2016, vol. 108, pp. 364-73.

23. A. Wagner, B.A. Shollock, and M. McLean: Mater. Sci. Eng. A, 2004, vol. 374, pp. 270-79. 
24. Y.M. Won and B.G. Thomas: Metall. Mater. Trans. A, 2001, vol. 32A, pp. 1755-67.

25. Y.T. Dai, Z.S. Xu, Z.P. Luo, K. Han, Q.J. Zhai, and H.X. Zheng: J. Magn. Magn. Mater., 2018, vol. 454, pp. 356-61.

26. J. Zeng, W.Q. Chen, and H.G. Zheng: Ironmak. Steelmak., 2017, vol. 44, pp. 676-84.
27. C.J. Song, W.B. Xia, J. Zhang, Y.Y. Guo, and Q.J. Zhai: Mater. Des., 2013, vol. 51, pp. 262-67.

Publisher's Note Springer Nature remains neutral with regard to jurisdictional claims in published maps and institutional affiliations. 